\title{
BRIEF REPORT \\ IMPLEMENTING A MEDITERRANEAN DIET INTERVENTION INTO A RCT: LESSONS LEARNED FROM A NON-MEDITERRANEAN BASED COUNTRY
}

\author{
G. MIDDLETON ${ }^{1}$, R. KEEGAN ${ }^{2}$, M.F. SMITH ${ }^{1}$, A. ALKHATIB ${ }^{3}$, M. KLONIZAKIS ${ }^{4}$ \\ 1. College of Social Sciences, School of Sport and Exercise Science, University of Lincoln, Lincoln, LN6 7TS, UK; 2. Faculty of Health, University of Canberra, Bruce, Australia; \\ 3. College of Arts and Sciences, Sport Science Program, Qatar University, Doha,Qatar, 2713, Qatar; 4. Centre for Sport and Exercise Science, Sheffield Hallam University, Sheffield, \\ Yorkshire, S10 2BP, UK. Corresponding author: G. Middleton, College of Social Sciences, School of Sport and Exercise Science, University of Lincoln, Lincoln, LN6 7TS, UK, \\ gmiddleton@lincoln.ac.uk
}

\begin{abstract}
Objective: To examine the participant experiences regarding perceived barriers and facilitators which impact on consuming the Mediterranean diet in the East of England. Design: Qualitative methodology with focus groups. Setting: A healthy, middle-aged population situated in the East of England. Intervention: An 8-week Mediterranean dietary intervention trial. Participants: Eleven participants (including three co-habiting partners) in three focus groups, ranging between 50-65yrs with a mean age of 54.3yrs $( \pm 4.0)$ Results: Thematic analysis from the focus groups revealed that participants considered that the MD intervention had introduced a better quality of food, widening the food-horizon and allowed them to re-define cultural eating habits. They also reported several physical benefits from adapting to this diet and found the experience as positive. Whilst claiming that the MD was an enjoyable and pleasurable, the participants did express difficulty adapting to the eating pattern, finding difficulty in purchasing food items, an increase in food costs and found work, stress and time pressures undermining adherence. Conclusion: The participants' experiences suggested that the MD was an encouraging dietary change with a middle aged non-Mediterranean based population group. Future MD interventions should tailor interventions and support participants closely, particularly with the necessary planning, organisation and purchasing involved with implementing this diet in non-Mediterranean countries. Secondly, researchers should also challenge any erroneous assumptions regarding the consumption of Mediterranean food, which may hinder implementation.
\end{abstract}

\section{Introduction}

In light of the accumulating scientific evidence, the Mediterranean diet (MD) is suggested to have a positive effect on cardiovascular health, particularly in relation to chronic disease development (1-4). Recommendations strongly encourage a Mediterranean-like dietary pattern for prevention of major chronic diseases $(5,6)$. In the United Kingdom, several credible organisations that provide dietary information have promoted consumption of the MD to the public, including NHS Choices (7) and Patient.co.uk (8). Little is known about the pragmatic and cultural perspectives of adopting the MD in this non-Mediterranean country and the concept of how British citizens incorporate a Mediterranean diet (MD) into daily life (e.g. food availability, cost, personal preferences and preparation) has remained unexplored. This study addresses this gap and highlights the barriers and facilitators to eating the MD, based on a small sample of British citizens who had participated in an experimental study in the north-east of England $(9,10)$. The previous study investigated the combined effects of the MD and an exercise intervention on lower- and upper-limb cutaneous microvascular function in a healthy middle-aged population.

\section{Methods}

This study was granted ethical approval by a University of Lincoln ethics committee. A qualitative methodology was employed to investigate participant experiences regarding barriers and facilitators which impacted upon their experience whist eating the MD during the experimental trial. This type of inquiry is important to investigate food-related behaviour, understanding 'how' and 'why' individuals act regarding food choices and consumption (11). This study used semi-structured focus groups with the expectation that rich contextual information from the participants' views and perspectives would be generated.

A purposive sample $(n=11)$ of adult participants, who had previously enrolled on an 8-week MD intervention study (9), was approached by email invitation. The invitation outlined the opportunity to discuss the experience of attempting the MD with other participants involved in the original study, in a University location at a mutually convenient time. All participants were encouraged to attend a focus group with their co-habiting partner (if relevant) to discuss their experiences at home during the trial. Each participant received a $£ 10$ shopping voucher for participation.

Eight of the eleven participants from the original study (9) took part in this study. Three co-habiting partners also attended. In total, 11 participants (mean age $=54.3 \pm 4.0$ years) attended three focus groups (mean time $=32 \pm 10$ minutes) which were staged up to two months after the original study at a University location at a mutually convenient time.

Focus group discussions were facilitated by the lead researcher and an experienced qualitative researcher and were 


\section{IMPLEMENTING A MEDITERRANEAN DIET INTERVENTION INTO A RCT}

audio recorded (supported by field notes). For consistency, a line of questioning was selected instead of a topic guide, for the semi-structured focus groups (12). Questions asked were designed to answer 'concept-driven' (13) research questions, exploring: 1) facilitators to the MD diet in the UK (e.g., "what was particularly enjoyable about the diet?"), and 2) barriers to the MD diet in the UK (e.g., "what difficulties did you face when buying the food items?"). Questions remained open to encourage explanations and foster discussion with probes and follow-up questions utilised (12). By keeping the structure relatively open, the participants discussed issues they viewed as important (14).

Researchers familiarised themselves with all recordings, which were listened to for familiarisation and transcribed verbatim. Data received thematic analysis via deductive and inductive processes. The following concept-driven questions created an organisational framework: 1) facilitators, and 2) barriers. Data were then given open codes (15), which were arranged in relation to which of the key questions they concerned, providing 'meaning units' (16) for either: 'barriers' or 'facilitators'. Following this, open codes were then inductively analysed into tentative categories and submitted to a process of constant comparison (17) to establish that: 1) the categories differed significantly from each other, and 2) the emerging themes were both embodied by the quotes within them, as well as being internally consistent (18). Throughout the analysis stages, interpretative coding (latent) was performed to examine participant ideas, assumptions and conceptualisations $(13,19)$.

The following processes were conducted to confirm the analysis: inter-rater checking (regarding the open coding process), consensus validation (regarding the organisation of themes), peer debrief and collaboration $(20,21)$.

\section{Results}

The following section has two main constructed themes from the conceptual questions on 'facilitators' and 'barriers', which are presented in bold. Themes emerging from the analysis are outlined in-text with italics. Table 1 provides an overview of the findings. Quotes are displayed with the speaker's reference given in the form: [participant number, focus group number].

\section{Facilitators}

The participants explained that the MD had been an enjoyable and pleasurable experience. Indeed, the attempt to integrate the diet into their lives had generated a sense of pleasure and fulfilment to meal times:

"we did enjoy it you know, especially when you finished work and you come home and you're tired and you've got some lovely Mediterranean food" [01,01].

As part of the MD intervention, the participants were asked to try a wide variety of Mediterranean foodstuffs with recipes and menus. Whilst attempting the various suggested meals, participants recognised that they had widened their foodhorizon. Secondly, they felt that the diet introduced a better quality of food into their normal eating habits:

"we're probably having fish at least three times a week... avocados too" [04, 02], and

"I stopped eating a lot of processed food" [05, 02].

Indeed, the diet had a socio-cultural impact on households with participants redefining cultural eating habits at meal-times and reporting changes to commensality with enhanced dining and eating experiences noticed:

"so I guess the benefits are in your lifestyle aren't they and your attitude to eating. We always sit at the table now as well" [04, 02].

Furthermore, since incorporating the diet, participants recognised and perceived that they had experienced several physical benefits related to adhering to the MD, which they regarded as important for their current health status:

"after I think about a month or so - I was beginning to feel a lot better a lot more easier, the size of my belly was coming down" [01,01].

\section{Barriers}

The participants reported challenges in adapting to the eating pattern, particularly at the start of the MD intervention. It was viewed that changes in organisation, preparation and purchasing food required substantial changes from the normal routines of participants:

"Time to prepare and more time to eat, is probably that ideal scenario around those types of foods isn't it?" [08, 03].

Participants did express difficulty in accommodating the diet with stress, work and time pressures undermining adherence. Intense periods of work and in some cases travelling commitments, were cited as real obstacles to sustained efforts to eat MD foods:

"it probably at times was a bit difficult to always stick to it because of, you know work and busy and whatever" [09, 03].

Furthermore, they viewed it as difficult to purchase food items in with little support to find and locate items in supermarkets, often spending extended time in stores, examining products:

"we needed to start reading labels, and that is confusing. So my husband buys something and I buy something and I say 'don't buy it in because it has too much'...'no it doesn't'....'let me see'..." [02, 01].

Additionally, it was indicated that adapting to this diet in England resulted in an increase in food costs for the participants involved:

"I found sometimes that I was maybe spending a bit more than I normally spend" [10,03].

The participants also viewed the British culture and climate as non-conducive to this pattern of eating, particularly in the autumn and winter months. They felt that comfort food and the temptations of other more traditional British foods were preferable in days when: 
Table 1

An overview of the emerging themes revealed by participants as barrier and facilitators to eating the Mediterranean diet

\begin{tabular}{lll}
\hline Concept-driven question topics: & Barriers & Facilitators \\
\hline Themes: & Adapting to the eating pattern & Enjoyable and pleasurable experience \\
& Stress, work and time pressures & Widened their food-horizon \\
& Difficult to purchase food items & Better quality of food \\
& Increase in food costs & Redefining cultural eating habits \\
& British culture and climate as non-conducive & Physical benefits \\
\hline
\end{tabular}

"you get your cold, damp, horrible miserable nights, the last thing you want to do is come back home and look at a salad" $[11,03]$.

\section{Discussion}

Findings revealed the enabling factors and apparent challenges when attempting to adhere to MD in a nonMediterranean country. Participants reported that the MD was challenging to implement over the 8-week intervention period. Indeed, the time involved in purchasing, organising and preparing food was cited as an imposing barrier for those in full-time employment with the additional pressures of time and family commitments. It was felt that more support was necessary to help establish a sustainable pattern of MD foods and the participants underestimated the extent of change from their usual diet. Furthermore, it became apparent that more time should be spent in explaining the variety of dishes and ingredients incorporated in MD, as the established notion that "salads are key MD dishes" appeared to be the case with some of the participants. This also illustrates some uncertainly to whether the participants' views about implementing the MD are commensurable with 'real-life' and whether erroneous assumptions are apparent (possibly on the Mediterranean lifestyle). Indeed, a limitation of this study is the inability of distinguishing whether the barriers faced are 'real' or just perceived. Even so, it is advisable to carefully consider the eating and lifestyle habits which complement the MD and how these factors are transferred to non-Mediterranean based populations attempting similar interventions (22). Additionally, it would be reasonable to assume that the cultural and lifestyle barriers encountered by non-Mediterranean population samples in intervention studies are more imposing factors to implementing the MD than those residing in Mediterranean countries, particularly in Southern Europe (2, 4, 5). Despite several epidemiological and prospective cohort studies in non-Mediterranean countries (USA and Northern Europe: 23-25), which have shown important associations between MD adherence and reducing cardiovascular risk, specific MD intervention studies in these regions are scarce.

Considering our findings regarding the facilitating factors, there is plenty of scope to implement tailored MD interventions in non-Mediterranean countries. The participants recognised that the change to their current diet was beneficial and that the intervention experience was worthwhile and pleasurable. They became more aware of food ingredients, fruit and vegetable seasons and improved the quality of the food that they consumed. Encouragingly, the 8-week MD intervention had allowed them to reconstruct dietary habits, mealtime routines and purchasing behaviours which illustrated an impactful change in the short-term.

We recommend that those with a public health role (physicians, nutritionists, researchers, practitioners and other advocates) that promote the MD in non-Mediterranean countries should provide tailored assistance for participants. The necessary planning, organisation and purchasing skills required to implement this diet (sourcing food, advising quantities of ingredients etc.) is of utmost importance to those attempting to follow this diet. Furthermore, they should challenge any stereotypical perceptions or assumptions which are thought to arise. This study has contributed to the development of appropriate MD interventions with nonMediterranean based populations, particularly those that reside in Western Europe. The ability to consistently support dietary change for a sustained period of time in a non-Mediterranean country is an apparent challenge and something in which the limited intervention studies in non-Mediterranean regions have yet to investigate despite promising health benefits $(9,10,26)$.

Ethics Declaration: This research was carried out in accordance with the Declaration of Helsinki of the World Medical Association and received ethical approval from a University of Lincoln Ethics Committee.

Acknowledgements: The authors would like to thank all the participants who took part in the study and the University of Lincoln's College of Social Science for the small grant to fund this investigation..

Conflict of Interest Disclosures: The authors do not have any conflicts of interest.

\section{References}

1. Chiva-Blanch G, Badimon L, Estruch, R. Latest Evidence of the Effects of the Mediterranean Diet in Prevention of Cardiovascular Disease. Curr Atheroscler Rep 2014;16:1-7

2. Estruch R, Ros E, Salas-Salvadó J et al. Primary prevention of cardiovascular disease with a Mediterranean diet. New Eng J Med 2013;368:1279-1290

3. Kopel E, Sidi Y, Kivity S, Estruch R, Ros E, Salas-Salvado J. Mediterranean diet for primary prevention of cardiovascular disease. New Eng J Med 2013;369: 672-672

4. Sofi F, Abbate R, Gensini GF, Casini A. Accruing evidence on benefits of adherence to the Mediterranean diet on health: an updated systematic review and meta-analysis. Am J Clin Nutr 2010;92:1189-96

5. Trichopoulou A, Martínez-González MA, Tong TY et al. Definitions and potential 


\section{IMPLEMENTING A MEDITERRANEAN DIET INTERVENTION INTO A RCT}

health benefits of the Mediterranean diet: views from experts around the world. BMC Med 2014;12:112-128

6. Bach-Faig A, Berry E, Lairon D et al. Mediterranean diet pyramid today. Science and cultural updates. Pub Health Nutr 2011;14:2274-2284

7. NHS Choices. What is a Mediterranean diet? http://www.nhs.uk/Livewell/Goodfood/ Pages/what-is-a-Mediterranean-diet.aspx. Accessed 28 Oct 2014

8. Patient.co.uk. How to Follow the Mediterranean Diet. http://www.patient.co.uk/ health/how-to-follow-the-mediterranean-diet. Accessed 28 Oct 2014

9. Klonizakis M, Alkhatib A, Middleton G, Smith MF. Mediterranean diet-and exercise-induced improvement in age-dependent vascular activity. Clin Sci 2013;124: 579-587

10. Klonizakis M, Alkhatib A, Middleton G. Long-term effects of an exercise and Mediterranean diet intervention in the vascular function of an older, healthy population. Microvasc Res 2014;95:103-107

11. Swift JA, Tischler V. Qualitative research in nutrition and dietetics: getting started. J Hum Nutr Diet 2010;23:559-566

12. Krueger R, Casey M. Focus Groups: A Practical Guide for Applied Research. 4th edn. Sage, London, 2009

13. Fade SA, Swift JA. Qualitative research in nutrition and dietetics: data analysis issues. J Hum Nutr Diet 2011;24:106-114

14. Bryman A. Social Research Methods, 3rd edn. Oxford University Press: Maidenhead,

15. Strauss A. Qualitative Analysis for Social Scientists. Cambridge University Press, Cambridge, 1987

16. Tesch R. Qualitative Research Analysis Types and Software Tools. Falmer Press, New York, USA, 1990
17. Strauss A, Corbin J. Basics of qualitative research: Grounded Theory, Procedures and Techniques. 3rd edn. Sage, London, 2008

18. Lincoln Y, Guba E. Naturalistic Inquiry. Sage, London, 1985

19. Braun V, Clarke V. Using thematic analysis in psychology. Qual Res Psychol 2006;3:77-101.

20. Cohen L, Manion L, Morrison K. Research Methods in Education. 5th edn. Routledge, London, 2000

21. Harris JE, Gleason PM, Sheean PM, Boushey C, Beto JA, Bruemmer B. An introduction to qualitative research for food and nutrition professionals. J Am Diet Assoc 2009;109:80-90

22. Hoffman R, Gerber, M. Evaluating and adapting the Mediterranean diet for nonMediterranean populations: a critical appraisal. Nut Rev 2013;71:573-584

23. Gardener $\mathrm{H}$, Wright $\mathrm{CB}, \mathrm{Gu} \mathrm{Y}$ et al. Mediterranean-style diet and risk of ischemic stroke, myocardial infarction, and vascular death: The Northern Manhattan Study. Am J Clin Nutr 2011;94:1458-1464

24. Rumawas ME, Meigs JB, Dwyer JT et al. Mediterranean-style dietary pattern, reduced risk of metabolic syndrome traits, and incidence in the Framingham Offspring Cohort. Am J Clin Nutr 2009;90:1608-1614

25. Knoops KT, de Groot LC, Kromhout D, et al. Mediterranean diet, lifestyle factors, and 10-year mortality in elderly European men and women: The HALE project. JAMA 2004;292:1433-1439

26. Goulet J, Lamarche B, Nadeau G, Lemieux S. Effect of a nutritional intervention promoting the Mediterranean food pattern on plasma lipids, lipoproteins and body weight in healthy French-Canadian women. Atherosclerosis 2003;170:115-124. 